\title{
Delayed sudden death after ingestion of MCPP and ioxynil: an unusual presentation of hormonal weedkiller intoxication
}

\author{
W. Dickey, J.J.A. McAleer and M.E. Callender \\ Royal Victoria Hospital, Grosvenor Road, Belfast BT12 6BA, UK.
}

\begin{abstract}
Summary: A patient who died in asystole less than $18 \mathrm{~h}$ after ingestion of 'Clovercide Extra', a combination hormonal weedkiller containing ioxynil and 4-chloro-2-methyl phenoxypropionic acid, is described. Previous reports describe coma as an early event following ingestion of these herbicides. In contrast our patient, although showing other characteristic features, including metabolic acidosis, tachycardia, pupillary constriction and pyrexia, remained conscious until the terminal event. Absence of coma does not appear to be related to a more favourable outcome.
\end{abstract}

\section{Introduction}

Hormonal weedkiller poisoning is usually associated with early coma. ${ }^{1-3}$ We describe a patient who remained conscious for over 17 hours before sudden fatal deterioration.

\section{Case report}

A 37 year old housewife presented 8 hours after the deliberate ingestion of $190 \mathrm{ml}$ of 'Clovercide Extra' (Synchemicals Ltd), containing $35 \mathrm{~g} / \mathrm{l}$ of ioxynil and $105 \mathrm{~g} / 1$ of 4-chloro-2-methyl phenoxypropionic acid (MCPP) in a hydrocarbon solvent. She was alert and orientated. Pulse was $100 / \mathrm{min}$, regular, blood pressure $130 / 80 \mathrm{~mm} \mathrm{Hg}$ and respiratory rate $25 / \mathrm{min}$. Examination was otherwise normal. Serum sodium, chloride and urea were normal but potassium was moderately elevated at $5.9 \mathrm{mmol} / 1$ (normal range 3.5-5.0). Liver enzyme activities and arterial blood gas analysis were normal. Creatine kinase was $3901 \mathrm{U} / 1$ (normal range 30-140). The electrocardiogram showed sinus tachycardia only. Oily liquid was obtained on gastric aspiration and lavage. A chest X-ray film taken 1 hour later was normal.

Ten hours after ingestion she suddenly became flushed and agitated. Her pulse was $130 / \mathrm{min}$, sinus rhythm, blood pressure unchanged and respiratory

Correspondence: W. Dickey, B.Sc., M.R.C.P. Accepted: 7 April 1988 rate $30 / \mathrm{min}$. Pupils were constricted but reacting and examination was otherwise normal. Arterialoc blood gas analysis showed a compensated metabolic acidosis: $\mathrm{pH} 7.34, \mathrm{PaCO}_{2} 3.5 \mathrm{kPa}$, base excess $-9.3 \mathrm{mmol} / \mathrm{l}$, standard bicarbonate $17.6 \mathrm{mmol} / \mathrm{l}$ and $\mathrm{PaO}_{2} \quad 9.7 \mathrm{kPa}$. Her agitation settled with oral diazepam.

Seventeen hours after ingestion her temperature suddenly rose to $39^{\circ} \mathrm{C}$. She was again treated symptomatically but rapidly developed generalized muscle rigidity and cardiac asystole. Immediate resuscitation was attempted. Laryngeal spasm necessitated cricothyroid puncture for airway insertion and there was considerable resistance to chest compression and inflation. She did not respond to intercardiac stimulants or transthoracic pacing.

Blood levels of MCPP were 515 and $451 \mathrm{mg} / \mathrm{l}$ at 8 hours and post-mortem respectively. Corresponding ioxynil levels were 317 and $299 \mathrm{mg} / \mathrm{l}$. Autopsy showed moderate pulmonary and cerebral oedema with early necrosis of the centrilobular liver parenchyma and renal tubules on microscopy. There was no obvious abnormality of skeletal or cardiac muscle on gross or microscopic examination.

\section{Discussion}

Although hormonal weedkillers are widely used, self-poisoning is rare. Four cases of ingestion of

(C) The Fellowship of Postgraduate Medicine, 1988 
combined MCPP and dichlorophenoxyacetic acid $(2,4 \mathrm{D})$ have been reported. Two patients developed coma within 2 hours, with tachycardia, pyrexia, meiosis and muscle rigidity. ${ }^{1,2}$

Investigations showed hyperkalaemia, raised serum creatine kinase and metabolic acidosis. One died in asystole, and post-mortem examination showed pulmonary oedema and liver necrosis. ${ }^{1}$ The other recovered after forced alkaline diuresis. ${ }^{2}$ Two other patients presented in coma, but without rigidity or pyrexia. ${ }^{3}$ Both had mild hypoxia and metabolic acidosis, but no elevation of creatine kinase, and both recovered with rehydration. MCPP levels in all cases were similar to those we report. We found no cases in the literature of MCPP poisoning alone, without $2,4 \mathrm{D}$. It is possible that the early development of coma in all these cases was due to ingestion of the latter.

We are aware of one reported case of fatal ioxynil ingestion. Death occurred 45 minutes after admission to hospital, and autopsy showed oedema of brain, liver and gut, with upper gastrointestinal erosions. ${ }^{4}$ These weedkillers cause uncoupling of

\section{References}

1. Osterloh, J., Lotti, M. \& Pond, S.M. Toxicologic studies in a fatal overdose of 2,4D, MCPP and chlorpyrifos. J Anal Toxicol 1983, 7: 125-129.

2. Prescott, L.F., Park, J. \& Darrien, I. Treatment of severe 2,4D and Mecoprop intoxication with alkaline diuresis. Br J Pharmacol 1979, 7: 111-116.

3. Wells, W.D.E., Wright, N. \& Yeoman, W.B. Clinical features and management of poisoning with 2,4D and Mecoprop. Clin Toxicol 1981, 18: 273-276. oxidative phosphorylation, and consequently hypercatabolic signs, including pyrexia, tachycardia, acidosis and sympathetic overactivity, would be expected to dominate the initial clinical picture, with subsequent evidence of skeletal muscle damage, including rigidity and raised serum potassium and muscle enzymes.

Forced alkaline diuresis may be beneficial. ${ }^{2}$ The clinical presentation is similar to that of malignant hyperthermia, ${ }^{5}$ which may suggest more specific therapy; unfortunately, the pathophysiology of the changes due to hormonal weedkiller ingestion has not been well defined. We suggest that patients who have taken hormonal weedkillers should be monitored under intensive care conditions regardless of level of consciousness.

\section{Acknowledgements}

We thank Dr D.J.L. Carson, T.D., M.D., Deputy State Pathologist, for permission to report the autopsy findings, and the Northern Ireland Forensic Laboratory for assay of MCPP and ioxynil.

4. Smysl, B., Smyslova, O. \& Kosatik, A. Akute todliche류 Ioxynilvergiftung. Arch Toxicol 1977, 37: 241-245.

5. Tomarken, J.L. \& Britt, B.A. Malignant hyperthermia Ann Emerg Med 1987, 16: 1253-1265. 